УДК 342.518

DOI: $10.35750 / 2071-8284-2020-2-165-171$

\author{
И. Е. Скоков \\ Санкт-Петербургский университет МВД России \\ Российская Федерачия, 198206, Санкт-Петербург, ул. Летчика Пилютова, д. 1 \\ ORCID: 0000-0002-4351-3223.E-mail: iga-spb74@mail.ru

\section{Некоторые проблемы оперативных подразделений полиции} \\ правового регулирования деятельности
}

\begin{abstract}
Аннотация: Введение. В статье рассматривается история правоприменения и внесения изменений в отдельные положения Федерального закона «О полиции» от 7 февраля 2011 г № 3-ФЗ. Цель. С позиции оперативно-розыскной деятельности и на основе сравнительно-правового метода познания провести анализ нормативных актов, регулирующих процесс правоохранительной и оперативно-розыскной деятельности, оценить отдельные положения Федерального закона «О полиции» и Федерального закона «Об оперативно-розыскной деятельности». Выявить проблемы взаимодействия указанных законов. В статье приводятся высказанные различными авторами несоответствия положений Федерального закона «О полиции» и Федерального закона «Об оперативно-розыскной деятельности». Результаты. В результате работы автором выявлены и отнесены к числу проблемных положения, касающиеся права сотрудников полиции на проведение оперативно-розыскных мероприятий, права на проникновение в жилища граждан и некоторые другие. Даются авторские предложения по внесению изменений в закон «О полиции», обусловливается необходимость дальнейших исследований, направленных на устранение выявленных недостатков и решение рассматриваемых проблем. Автор приходит к выводу, что своевременное устранение недостатков правовой взаимосвязи Ф3 «О полиции» и Ф3 «Об ОРД» в контексте регулирования деятельности оперативных подразделений полиции будет только способствовать повышению эффективности организации оперативно-розыскной деятельности органов внутренних дел.
\end{abstract}

Ключевые слова: полиция, права полиции, оперативные подразделения, оперативно-розыскная деятельность, оперативно-розыскные мероприятия.

Для цитирования: Скоков И. Е. Некоторые проблемы правового регулирования деятельности оперативных подразделений полиции // Вестник Санкт-Петербургского университета МВД России. - 2020. - № 2 (86). - C. 165-171. DOI: 10.35750/2071-8284-2020-2-165-171.

Igor E. Skokov

Saint-Petersburg University of the MIA of Russia

1, Letchika Pilyutova str., Saint-Petersburg, 198206, Russian Federation ORCID: 0000-0002-4351-3223.E-mail: iga-spb74@mail.ru

\title{
Certain problems of legal regulation of the activities of operational police units
}

Annotation: Introduction. The article deals with the history of the law enforcement and alteration to certain provisions of the Federal law «On police» from 07.02.2011 № 3-FZ. Goal. The purpose of the work was to evaluate certain provisions of the Federal law «On police» and the Federal law «On operational and investigative activities» from the point of view of operational search activity and on the basis of a comparative legal method of cognition of normative acts regulating the process of law enforcement and operational search activity. To identify the problems of the interaction of these laws. The article presents inconsistencies between the provisions of the Federal law «On police» and the Federal law «On operational and investigative 
activities». Results. As a result of the work, the author identified and attributed to the number of problematic provisions concerning the right of police officers to conduct operational search activities, the right to enter the homes of citizens, and some others. The author's suggestions for amendments to the law «On police» are given, and the need for further research aimed at eliminating the identified shortcomings and solving the problems under consideration is determined. The author comes to the conclusion that the timely elimination of the shortcomings of the legal relationship between the Federal law «On police» and the Federal law «On operational and investigative activities» in the context of regulating the activities of operational police units will only increase the efficiency of the organization of operational and investigative activities of the internal affairs bodies.

Keywords: police, police rights, operational units, operational search activities, operational search inquiries.

For citation: Skokov I. E. Certain problems of legal regulation of the activities of operational police units // Vestnik of St. Petersburg University of the Ministry of Internal Affairs of Russia. - 2020. - № 2 (86). - P. 165-171. DOI: 10.35750/2071-8284-2020-2-165-171.

Федеральный закон от 7 февраля 2011 г. № 3-Ф3 «О полиции», действующий на территории Российской Федерации уже десятый год и регулирующий правовые отношения, возникающие в процессе правоохранительной деятельности полиции, за весь период своего существования претерпел уже более сорока изменений ${ }^{1}$.

Все изменения, внесённые в данный закон, так или иначе были призваны сделать работу полиции ещё более эффективной и помогали решить такие проблемы, о возникновении которых зачастую и не могли предполагать создатели первой редакции данного закона. Так, например, пункт 40 статьи 13 и пункт 5 части 3 статьи 24 данного закона предусматривают возможность для сотрудников полиции пресекать нахождение беспилотных воздушных судов в воздушном пространстве в целях защиты жизни, здоровья и имущества граждан над местом проведения публичного (массового) мероприятия и прилегающей к нему территории, проведения неотложных следственных действий и оперативно-розыскных мероприятий. Такое пресечение осуществляется посредством подавления или преобразования сигналов дистанционного управления беспилотными воздушными судами, воздействия на их пульты управления, а также повреждения или уничтожения данных судов. Согласно введённым изменениям, порядок принятия решения о пресечении нахожде-

${ }^{1}$ О полиции : Федеральный закон от 7 февраля 2011 г. № 3-Ф3 [Электронный ресурс] // СПС «Консультант-плюс». - Режим доступа: http://www.consultant.ru/document/cons_ doc_LAW_110165/ (дата обращения: 20.02.2020). ния беспилотных воздушных судов в воздушном пространстве в указанных целях, а также перечень должностных лиц полиции, уполномоченных на принятие такого решения, определяется руководителем федерального органа исполнительной власти в сфере внутренних дел. Сотрудникам полиции внесёнными изменениями предоставляется право вплоть до возможности применения огнестрельного оружия для пресечения нахождения беспилотных воздушных судов в воздушном пространстве в целях, предусмотренных указанным пунктом закона, если иными средствами прекратить их нахождение в воздушном пространстве не представляется возможным ${ }^{2}$. Понятно, что в 2011 году о появлении такой необходимости мало кто задумывался.

На определённые проблемы, связанные с некоторым несоответствием положений Федерального закона «О полиции» положениям Федерального закона от 12 августа 1995 г. № 144-Ф3 «Об оперативно-розыскной деятельности» ${ }^{3}$, обращали внимание такие авторы, как Н. С. Железняк [1, с. 6-16], представивший свою позицию по проблемным вопросам ещё на стадии

${ }^{2} \mathrm{O}$ внесении изменений в отдельные законодательные акты Российской Федерации : Федеральный закон от 2 декабря 2019 г. № 404-Ф3 [Электронный ресурс] // СПС «Консультант-плюс». - Режим доступа: http://www. consultant.ru/document/cons_doc_LAW_339113/5bdc78bf7e 3015a0ea0c0ea5bef708a6c79e2f0a/\#dst100040 (дата обращения: 20.02.2020).

${ }^{3}$ Об оперативно-розыскной деятельности : Федеральный закон от 12 августа 1995 г. № 144-Ф3 [Электронный ресурс] // СПС «Консультант-плюс». - Режим доступа: http://www.consultant.ru/document/cons_doc_LAW_110165 (дата обращения: 20.02.2020). 
обсуждения закона «О полиции», а затем в своей монографии рассмотревший соотношение задач ОРД и основных направлений деятельности полиции, содержащихся в статье 2 Ф3 «О полиции» [2, с. 24]; Е. А. Летаева [3, с. 125], отметившая в своей работе применение полицией мер государственного принуждения, не нашедших отражения в Ф3 «О полиции»; А. И. Музеев [4, c. 51], обративший внимание на разногласие между нормами, изложенными в статье 12 закона «О полиции», и статьей 1 закона «Об ОРД», в результате чего, по мнению автора, данное обстоятельство приводит, с одной стороны, к восприятию правоприменителем целей ОРД полиции как отличных от целей оперативно-розыскной деятельности в целом, а с другой стороны - к недопустимому смешению различных по значению категорий. А. А. Ребров и М. А. Лобанов в своем исследовании рассмотрели проблему «урезанности» ${ }^{4}$ полномочий сотрудников оперативных подразделений полиции, в том числе и в праве вызывать в полицию граждан и должностных лиц в установленном порядке, предусмотренном в п. 3 ч. 1 статьи 11 Ф3 «О полиции», так как законодатель управомочивает это делать лишь «по расследуемым уголовным делам и находящимся в производстве делам об административных правонарушениях, а также в связи с проверкой зарегистрированных в установленном порядке заявлений и сообщений о преступлениях об административных правонарушениях, о происшествиях» [5, с. 28]. В качестве положительного примера, в котором приведённые нормы рассматриваемых законов логичным образом, не противореча, дополняют друг друга, можно привести исследование Д. Г. Шашина, который в ходе изучения проблемы получения оперативными подразделениями органов внутренних дел информации от кредитных организаций при выявлении, предупреждении, пресечении и раскрытии преступлений, связанных с незаконным оборотом наркотиков, обратил внимание на то, что действия сотрудников оперативных подразделений полиции по направлению запросов в кредитные организации обусловлены выполнением возложенных на них обязанностей по выявлению, предупреждению, пресечению и раскрытию преступлений, а также отметил тот факт, что указанные действия соответствуют правам сотрудников органов

\footnotetext{
${ }^{4}$ Такой термин использован авторами статьи.
}

внутренних дел, а предоставление информации, отнесённой к профессиональной тайне, по запросам полиции не может быть расценено как её разглашение, что согласуется соответственно с п. 10 ч. 1 статьи 13 Ф3 «О полиции» и статьёй 6 Ф3 «Об ОРД» $[6$, с. 80], и др.

Тем не менее необходимость внесения в данный закон поправок не исчерпывается изменениями, вносимыми вслед за событиями, происходящими в ходе развития общества и общественных отношений. На наш взгляд, в данном законе еще есть позиции, которые нуждаются в осмыслении и корректировке, позволяющей их усовершенствовать.

В соответствии со статьей 4 Ф3 «О полиции» полиция является составной частью единой централизованной системы федерального органа исполнительной власти в сфере внутренних дел 5 В состав полиции входят, наряду с другими организациями и службами, подразделения, на которые возлагаются функции по осуществлению оперативно-розыскной деятельности, оперативно-поисковых и специальных технических мероприятий ${ }^{6}$.

В п. 10 статьи 13 Ф3 «О полиции», согласно ч. 1 данной статьи, полиции для выполнения возложенных на нее обязанностей предоставляется в том числе право проводить оперативнорозыскные мероприятия ${ }^{7}$ использовать в целях конспирации документы, зашифровывающие сведения о сотрудниках органов внутренних дел, ведомственной принадлежности их подразделений, организаций и служб, помещений и транспортных средств, обрабатывать сведения о сотрудниках органов внутренних дел, содержащиеся в государственных информационных системах и (или) базах данных государственных органов и государственных внебюджетных фондов; производить при осуществлении оперативно-розыскной деятельности изъятие документов, предметов, материалов и сообщений и иные, предусмотренные федеральным зако-

${ }^{5}$ О полиции : Федеральный закон от 7 февраля 2011 г. № 3-Ф3 [Электронный ресурс] // СПС «Консультант-плюс». - Режим доступа: http://www.consultant.ru/document/cons_ doc_LAW_110165/ (дата обращения: 20.02.2020).

${ }^{6}$ Вопросы организации полиции : Указ Президента РФ от 1 марта 2011 г. № 250, ч. 1, п. Ж (в ред. от 7 декабря 2016 г.) [Электронный ресурс] // СПС «Консультант-плюс». - Режим доступа: http://www.consultant.ru/document/cons_ doc_LAW_111137/ (дата обращения 25.02.2020).

${ }^{7}$ Далее ОРМ. 
ном, действия; объявлять розыск и принимать меры по розыску лиц, совершивших преступления или подозреваемых и обвиняемых в их совершении, лиц, пропавших без вести, иных лиц, розыск которых возложен на полицию настоящим Федеральным законом, а также объявлять розыск и принимать меры по розыску похищенных или угнанных транспортных средств, похищенного имущества, имущества, подлежащего конфискации ${ }^{8}$.

Оставляя в стороне вопрос различия терминологических понятий «оперативно-розыскной» (как в ФЗ «Об ОРД») и «оперативно-разыскной» деятельности, как в Ф3 «О полиции», так как изучением данного вопроса уже занималось значительное количество других авторов 9 [5, с. $26 ; 7$, с. $34-37 ; 8$, с. $9 ; 9$, с. $80-84 ; 10$, с. 85 ], хотелось бы обратить внимание на то, что в данной норме присутствует определенное несоответствие с положениями федерального закона «Об ОРД», где в статье 1 понятие оперативно-розыскной деятельности ${ }^{10}$ определено как вид деятельности, осуществляемой гласно и негласно оперативными подразделениями государственных органов, уполномоченных на то настоящим Федеральным законом (далее - органы, осуществляющие оперативно-розыскную деятельность), в пределах их полномочий посредством проведения оперативно-розыскных мероприятий в целях защиты жизни, здоровья, прав и свобод человека и гражданина, собственности, обеспечения безопасности общества и государства от преступных посягательств ${ }^{11}$.

В настоящее время перечень оперативных подразделений системы МВД России, правомочных осуществлять оперативно-розыскную деятельность, утвержден приказом МВД России от 19 июня 2012 г. № 608 «О некоторых вопросах организации оперативно-розыскной деятель-

${ }^{8} \mathrm{O}$ полиции : Федеральный закон от 7 февраля 2011 г. № 3-Ф3. - Ст. 13 [Электронный ресурс] // СПС «Консультант-плюс». - Режим доступа: http://www. consultant.ru/document/cons_doc_LAW_110165/ (дата обращения: 20.02.2020).

${ }^{9}$ Сурначева Е. И. Полиция против Розенталя [Электронный ресурс] // Сайт «Газета.Ру». - 2011. - 10 фев. URL: https://www.gazeta.ru/politics/2011/02/10_a_3519978. shtml (дата обращения 01.03.2020).

${ }^{10}$ Далее ОРД.

${ }^{11}$ Об оперативно-розыскной деятельности : Федеральный закон от 12 августа 1995 г. № 144-ФЗ. - Ст. 1 [Электронный ресурс] // СПС «Консультант-плюс». - Режим доступа: http://www.consultant.ru/document/cons_doc_ LAW_110165 (дата обращения: 20.02.2020). ности в системе МВД России» ${ }^{12}$, однако в п. 10 ст. 13 закона о возможности осуществления ОРД только сотрудниками оперативных подразделений не говорится. Нет такого упоминания и в других частях данной статьи, как, например, в положении ч. 2 ст. 13, говорящем о том, что право осуществлять действия, предусмотренные пунктами 20 и 21 части 1 статьи 13 закона (право останавливать транспортные средства, временно ограничивать или запрещать дорожное движение, задерживать транспортные средства и отстранять водителей от управления транспортными средствами и ряд других прав, касающихся безопасности дорожного движения), предоставляется специально уполномоченным сотрудникам полиции.

Данные противоречия могут привести, на наш взгляд, к нарушению прав и свобод граждан при осуществлении ОРД полицией. Устранение названных противоречий возможно посредством приведения в соответствие указанных норм, а именно, в части 1 пункт 10 изложить в следующей редакции: «10) оперативные подразделения полиции, осуществляя оперативно-розыскную деятельность посредством проведения оперативно-розыскных мероприятий, сочетания гласных и негласных методов и средств, вправе использовать в целях конспирации документы, зашифровывающие сведения о сотрудниках органов внутренних дел, ведомственной принадлежности их подразделений, организаций и служб, помещений и транспортных средств», далее по тексту.

Отдельной проблемой, требующей серьезного изучения с целью разрешения имеющихся противоречий, является соотношение содержащихся в статье 15 Ф3 «О полиции» норм, которые гарантируют такое конституционное право, как неприкосновенность жилища. Представляется, что содержащиеся в статье положения не учитывают специфику действий оперативных подразделений полиции. Согласно п. 6, п. 6.1 и п. 7 данной статьи, «О каждом случае проникновения сотрудника полиции в жилое помещение в возможно короткий срок, но не позднее 24 часов с момента проникновения, информируются

${ }^{12} \mathrm{O}$ некоторых вопросах организации оперативнорозыскной деятельности в системе МВД России : Приказ МВД России от 19 июня 2012 г. № 608 (в ред. от 1 июля 2019 г.) [Электронный ресурс] // СПС «Консультантплюс». - Режим доступа http://www.consultant.ru/document/ cons_doc_LAW_133312/ (дата обращения 15.02.2020). 
собственник этого помещения и (или) проживающие там граждане, если такое проникновение было осуществлено в их отсутствие. О каждом случае проникновения сотрудника полиции в нежилое помещение или на земельный участок при обстоятельствах, указанных в части 4 статьи, в возможно короткий срок, но не позднее 24 часов с момента проникновения, информируется в порядке, установленном федеральным органом исполнительной власти в сфере внутренних дел, собственник нежилого помещения или земельного участка либо его законный представитель, если такое проникновение было осуществлено в его отсутствие (хотелось бы отметить, что данный пункт был введен Федеральным законом от 6 февраля 2020 г. № 12-Ф3). О каждом случае вхождения сотрудника полиции в жилое помещение, помимо воли находящихся там граждан, письменно уведомляется прокурор в течение 24 часов $^{13}$. Противоречие с законом «Об ОРД» видится в том, что в статье 6 данного закона предусматривается возможность проведения такого ОРМ, как «Обследование помещений, зданий, сооружений, участков местности и транспортных средств». Данное оперативнорозыскное мероприятие на основании статьи 1 указанного закона может проводиться, как и все остальные ОРМ, как гласным, так и негласным способом. Второй вариант подразумевает в

${ }^{13}$ О полиции : Федеральный закон от 7 февраля 2011 г. № 3-Ф3 [Электронный ресурс] // СПС «Консультант-плюс». - Режим доступа: http://www.consultant.ru/document/cons_ doc_LAW_110165/ (дата обращения: 20.02.2020). рамках соблюдения принципа конспирации ${ }^{14}$ не только неуведомление собственника, но и принятие мер к сохранению от него в тайне самого факта проведения данного ОРМ. В этом случае соблюдение норм Ф3 «О полиции» будет выглядеть как минимум нелогично, а точнее, будет прямо противоречить нормам Ф3 «Об ОРД», относящимся к защите сведений об органах, осуществляющих ОРД ${ }^{15}$. Решение данной проблемы возможно как посредством внесения изменений в соответствующие статьи Ф3 «О полиции» с учётом специфики осуществления ОРД, так и посредством внесения изменений в Ф3 «Об ОРД».

Так, один из вариантов решения проблемы со стороны изменений правового поля оперативно-розыскной деятельности авторитетный учёный, доктор юридических наук В. Ф. Луговик видит в принятии новой редакции закона «Об ОРД», но уже в виде кодекса «Об оперативно-розыскной деятельности» $[11$, c. $58 ; 12$, с. 15$]$.

Таким образом, своевременное устранение недостатков правовой взаимосвязи ФЗ «О полиции» с Ф3 «Об ОРД» в контексте регулирования деятельности оперативных подразделений полиции, на наш взгляд, будет только способствовать повышению эффективности организации ОРД органов внутренних дел.

${ }^{14}$ Об оперативно-розыскной деятельности : Федеральный закон от 12 августа 1995 г. № 144-Ф3 [Электронный ресурс] // СПС «Консультант-плюс». - Режим доступа: http://www.consultant.ru/document/cons_doc_LAW_110165 (дата обращения: 20.02.2020).

${ }^{15}$ Там же. - Ст. 12.

\section{Список литературь}

1. Железняк Н. С. Комментарии к проекту Федерального закона «О полиции» (оперативнорозыскной аспект) // Вестник Сибирского юридического института МВД России. - 2010. - № 4 (8). - C. $6-16$

2. Железняк Н. С. Вопросы актуализации Федерального закона «Об оперативно-розыскной деятельности». - Красноярск: Сибирский юридический институт МВД России, 2019. - 332 с.

3. Летаева Е. А. Применение полицией мер государственного принуждения, не нашедших отражение в Федеральном законе от 07.02.2011 г. № 3-Ф3 «О полиции» // Полиция и общество: проблемы и перспективы взаимодействия. - 2019. - № 1 (3). - С. 124-129.

4. Музеев А. И. Некоторые проблемы правового регулирования организации оперативнорозыскной деятельности органов внутренних дел по борьбе с бандитизмом // Вестник Казанского юридического института МВД России. - 2011. - № 4 (6). - С. 50-56.

5. Лобанов М. А., Ребров А. А. Некоторые проблемы регулирования Федеральным законом «О полиции» отношений в сфере ОРД // Законы России: опыт, анализ, практика. - 2013. - № 3. - C. 25-29. 
6. Шашин Д. Г. К проблеме получения оперативными подразделениями органов внутренних дел информации от кредитных организаций при выявлении, предупреждении, пресечении и раскрытии преступлений, связанных с незаконным оборотом наркотиков // Вестник Сибирского юридического института МВД России. - 2019. - № 2 (35). - С. 77-82.

7. Красинский В. В. О соотношении понятий «оперативно-розыскная деятельность» и «оперативно-разыскная деятельность» // Современное право. - 2012. - № 8. - С. 34-37.

8. Шумилов А. Ю. О назревшей в теории проблеме разделения прежней оперативно-розыскной и современной оперативно-разыскной деятельности: взгляд сысколога // Оперативник (сыщик). - 2014. - № 1 (38). - С. 8-17.

9. Захариев С. И., Безбородова Ю. Ю. Наука оперативно-розыскной деятельности: вопросы правописания // Юридическая наука: история и современность. - 2014. - № 10. - С. 80-84.

10. Катков С. В. Проблемы ведомственного нормативно-правового регулирования деятельности подразделений экономической безопасности и противодействия коррупции органов внутренних дел по выявлению, пресечению и раскрытию экономических преступлений, связанных с внешнеэкономической деятельностью / Оперативно-разыскное право : сборник материалов конференции. - Волгоград: Волгоградская академия МВД России, 2015. - С. 83-91.

11. Луговик В. Ф. Направления совершенствования правового регулирования оперативнорозыскной деятельности органов внутренних дел / Актуальные проблемы теории и практики оперативно-разыскной деятельности : сборник трудов IV Всероссийской научно-практической конференции. - Краснодар: Краснодарский университет МВД России, 2016. - С. 53-59.

12. Луговик В. Ф. О проекте оперативно-разыскного кодекса Российской Федерации. краткая история законодательного регулирования оперативно-разыскной деятельности / Актуальные вопросы законодательного регулирования оперативно-разыскной деятельности : сборник трудов конференции (Омск, 18 ноября 2014 г.). - Омск: Омская академия МВД России, 2015. - C. 3-22.

\section{References:}

1. Zheleznyak N. S. Kommentarii k proyektu Federal'nogo zakona «O politsii» (operativnorozysknoy aspekt) // Vestnik Sibirskogo yuridicheskogo instituta MVD Rossii. - 2010. - № 4 (8). S. $6-16$

2. Zheleznyak N. S. Voprosy aktualizatsii Federal'nogo zakona «Ob operativno-rozysknoy deyatel'nosti. - Krasnoyarsk: Sibirskiy yuridicheskiy institut MVD Rossii, 2019. - 332 s.

3. Letayeva Ye. A. Primeneniye politsiyey mer gosudarstvennogo prinuzhdeniya, ne nashedshikh otrazheniye v Federal'nom zakone ot 07.02.2011 g. № 3-FZ «O politsii» // Politsiya i obshchestvo: problemy i perspektivy vzaimodeystviya. - 2019. - № 1 (3). - S. 124-129.

4. Muzeyev A. I. Nekotoryye problemy pravovogo regulirovaniya organizatsii operativnorozysknoy deyatel'nosti organov vnutrennikh del po bor'be s banditizmom // Vestnik Kazanskogo yuridicheskogo instituta MVD Rossii. - 2011. - № 4 (6). - S. 50-56.

5. Lobanov M. A., Rebrov A. A. Nekotoryye problemy regulirovaniya Federal'nym zakonom «O politsii» otnosheniy v sfere ORD // Zakony Rossii: opyt, analiz, praktika. - 2013. - № 3. - S. 25-29

6. Shashin D. G. K probleme polucheniya operativnymi podrazdeleniyami organov vnutrennikh del informatsii ot kreditnykh organizatsiy pri vyyavlenii, preduprezhdenii, presechenii i raskrytii prestupleniy, svyazannykh s nezakonnym oborotom narkotikov // Vestnik Sibirskogo yuridicheskogo instituta MVD Rossii. - 2019. - № 2 (35). - S. 77-82.

7. Krasinskiy V. V. O sootnoshenii ponyatiy «operativno-rozysknaya deyatel'nost'» i «operativnorazysknaya deyatel'nost'» // Sovremennoye pravo. - 2012. - № 8. - S. 34-37.

8. Shumilov A. Yu. O nazrevshey v teorii probleme razdeleniya prezhney operativno-rozysknoy $\mathrm{i}$ sovremennoy operativno-razysknoy deyatel'nosti: vzglyad syskologa // Operativnik (syshchik). - 2014. - № 1 (38), - S. 8-17.

9. Zakhartsev S. I., Bezborodova Yu. Yu. Nauka operativno-rozysknoy deyatel'nosti: voprosy pravopisaniya // Yuridicheskaya nauka: istoriya i sovremennost. - 2014. - № 10. - S. 80-84. 
10. Katkov S. V. Problemy vedomstvennogo normativno-pravovogo regulirovaniya deyatel'nosti podrazdeleniy ekonomicheskoy bezopasnosti i protivodeystviya korruptsii organov vnutrennikh del po vyyavleniyu, presecheniyu i raskrytiyu ekonomicheskikh prestupleniy, svyazannykh s vneshneekonomicheskoy deyatel'nost'yu / Operativno-razysknoye parvo : sbornik materialov konferentsii. - Volgograd: Volgogradskaya akademiya MVD Rossii, 2015. - S. 83-91.

11. Lugovik V. F. Napravleniya sovershenstvovaniya pravovogo regulirovaniya operativnorozysknoy deyatel'nosti organov vnutrennikh del / Aktual'nyye problemy teorii i praktiki operativnorazysknoy deyatel'nosti : sbornik trudov IV Vserossiyskoy nauchno-prakticheskoy konferentsii. Krasnodar: Krasnodarskiy universitet MVD Rossii, 2016 g. - S. 53-59.

12. Lugovik V. F. Oproyekte operativno-razysknogo kodeksa Rossiyskoy Federatsii. kratkaya istoriya zakonodatel'nogo regulirovaniya operativno-razysknoy deyatel'nosti / Aktual'nyye voprosy zakonodatel'nogo regulirovaniya operativno-razysknoy deyatel'nosti : sbornik trudov konferentsii (Omsk, 18 noyabrya 2014 g.). - Omsk: Omskaya akademiya MVD Rossii, 2015. - S. 3-22.

(С Скоков И. Е., 2020

Статья поступила в редакцию 30.03.2020 г. 